\title{
Atributos de fertilidade dos solos sob vegetação nativa do bioma cerrado
}

Objetivou-se com este estudo avaliar os atributos de fertilidade dos solos em áreas de vegetação nativa do Estado de MS, visando gerar informações de referência para tomadas de decisões no uso do recurso solo. Foram coletadas amostras de solos deformadas em 13 pontos amostrais em remanescentes de vegetação nativa, nas profundidades de 0,0 a 0,20 m e 0,20 a 0,40 m. As análises químicas: $\mathrm{pH}$ em CaCl2, P, K+, $\mathrm{Ca} 2+, \mathrm{Mg} 2+, \mathrm{Al} 3+, \mathrm{H}+\mathrm{Al}, \mathrm{M} . \mathrm{O}$ e índices de fertilidade calculados ( $\mathrm{SB}$ $\mathrm{CTC}$ a pH 7,0 e V\%) bem como a granulometria (areia, silte e argila) foram determinadas conforme metodologias da Embrapa. Os dados obtidos foram avaliados por estatística descritiva e análise de componentes principais. A fertilidade dos solos sob remanescentes de vegetação nativa está intimamente ligada ao materia de parental e aos processos pedogenéticos. Os solos MD, NV, RR e PVA apresentam alta fertilidade natural evidenciados pelos altos valores de CTC, SB e V\%. A baixa fertilidade natural dos solos SX, LV e GX está associada aos altos teores de Al3+e H+Al+e valores baixos de pH e V\%. Os solos LV e NV por possuírem maiores teores de argila podem contribuir com maior capacidade de retenção de água e fornecimento de nutrientes favoráveis ao desenvolvimento de plantas. Os solos GX e SX por possuírem características químicas indesejáveis para atender à demanda das plantas, como baixos teores de nutrientes e acidez elevada, localizam próximos as nascentes e aos cursos d'água, por isso devem deixá-los como áreas de preservação da fauna e flora e de mananciais hídricos. Os solos RR e MD esses apresentam limitações ao uso agrícola como pequena profundidade que impede uma boa retenção e infiltração de água, dificuldade de mecanização e risco à erosão. $\mathrm{O}$ conhecimento dos atributos de fertilidade do solo é importante para manejo adequado, tanto para a manutenção da vegetação nativa, quanto para maior aproveitamento do solo em determinado uso, resultando em economia ao homem e a própria natureza, evitando tomadas de decisões errôneas na utilização dos recursos naturais.

\section{Fertility attributes of soils under native vegetation in the cerrado bioma}

\begin{abstract}
The objective of this study was to evaluate the fertility attributes of soils in areas of native vegetation in the State of MS to generate reference information for decision-making in the use of the soil resource. Samples of deformed soils were collected at thirteen points, in remnants of native vegetation, at depths of 0.0 to $0.20 \mathrm{~m}$ and 0.20 to $0.40 \mathrm{~m}$. The chemical analyses determined were: $\mathrm{pH}$ in $\mathrm{CaCl} 2, \mathrm{P}, \mathrm{K}+, \mathrm{Ca} 2+, \mathrm{Mg} 2+, \mathrm{Al} 3+, \mathrm{H}+\mathrm{Al}, \mathrm{MO}$ and calculated fertility indices ( $\mathrm{SB}, \mathrm{CTC}$ at $\mathrm{pH}$ 7.0 and V\%) as well as the particle size (sand, silt, and clay). The data obtained were evaluated by descriptive statistics and principal component analysis. Parental material and pedogenetic processes are closely related to soil fertility under remnants of native vegetation. MD, NV, RR, and PVA soils have high natural fertility, evidenced by CTC, SB, and V\%. The low natural fertility of SX, LV, and GX soils is associated with high levels of Al3+ and $\mathrm{H}+\mathrm{Al}+$ and low values of pH and V\%. Because they have higher clay contents, the LV and NV soils can contribute to greater water retention capacity and nutrients favorable to plant development. The GX and SX soils have undesirable chemical characteristics to meet the demand of plants, so they should be left as areas of fauna and flora, and water sources. The RR and MD soils have limitations for agricultural use, such as a small depth that prevents good retention and infiltration of water, difficulty in mechanization, and risk of erosion. The knowledge of soil fertility attributes is essential for proper management, both for the maintenance of native vegetation and for greater use of the soil in a given service, resulting in savings for man and nature itself, avoiding erroneous decision-making in the use of natural resources.
\end{abstract}

Keywords: Tropical soils; Soil quality; Reference soils; Soil conservation; Principal component analysis.

Topic: Ciências do Solo

Reviewed anonymously in the process of blind peer
Received: 02/07/2021 Approved: 27/07/2021
Alves Alexandre Alovisi (iD

Universidade Federal da Grande Dourados, Brasil http://lattes.cnpq.br/5917323543322184 http://orcid.org/0000-0002-5401-717X

alves.snpconsultoria@gmail.com

\section{Cleidimar João Cassol (iD}

Universidade Federal da Grande Dourados, Brasil http://lattes.cnpq.br/8446412417215481 http://orcid.org/0000-0002-2433-7084 cleidimar_cassol@hotmail.com

Alessandra Mayumi Tokura Alovisi (iD Universidade Federal da Grande Dourados, Brasil http://lattes.cnpq.br/5030383787014962

https://orcid.org/0000-0003-4236-4446 alessandraalovisi@ufgd.edu.br

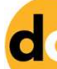

DOI: 10.6008/CBPC2179-6858.2021.007.0004

\author{
Luiz Carlos Ferreira de Souza (iD) \\ Universidade Federal da Grande Dourados, Brasil \\ http://lattes.cnpq.br/5733457300125227 \\ http://orcid.org/0000-0002-9216-5077 \\ luizsouza@ufgd.edu.br \\ Eduardo José de Arruda (iD \\ Universidade Federal da Grande Dourados, Brasil \\ http://lattes.cnpq.br/3624370723788970 \\ https://orcid.org/0000-0002-9835-467X \\ eduardoarruda@ufgd.edu.br \\ Robervaldo Soares da Silva (iD \\ Universidade Federal da Grande Dourados, Brasil \\ http://lattes.cnpq.br/8840224083901788 \\ http://orcid.org/0000-0002-0214-4820 \\ robervaldo.soares@yahoo.com.br
}

\section{Referencing this:}

ALOVISI, A. A.; CASSOL, C. J.; TOKURA, A. M.; SOUZA, L. C. F.; ARRUDA, E. J.; SILVA, R. S.. Atributos de fertilidade dos solos sob vegetação nativa do bioma cerrado. Revista Ibero Americana de Ciências Ambientais, v.12, n.7, p.38-52, 2021. DOI:

http://doi.org/10.6008/CBPC2179-6858.2021.007.0004 


\section{INTRODUÇÃO}

O conhecimento sobre as aptidões e restrições do território tem sido necessário para disciplinar os usos e a ocupação da terra (LOPES et al., 2019). A interferência do homem no meio ambiente e a utilização inadequada das terras vêm gerando, ao longo do tempo, a insustentabilidade dos recursos naturais. As práticas de manejo do solo vêm sendo adaptadas a interesses imediatos, em virtude do crescimento populacional, da intensificação de áreas urbanizadas e das demandas por serviços básicos. Os solos vêm perdendo sua capacidade de sustentar a produtividade biológica e manter sua qualidade em benefício da saúde animal e vegetal, considerando seus diferentes usos (RODRÍGUEZ-EUGENIO et al., 2018).

Em condições naturais, o solo coberto por vegetação é pouco sujeito a processos de degradação, devido à manutenção do equilíbrio ambiental existente. Quando a vegetação é retirada, para ocupação do solo pela agricultura ou outras atividades, ocorre perda de matéria orgânica e nutrientes e redução da infiltração de água, fazendo com que o solo perca uma de suas mais importantes funções, que é de atuar como filtro ambiental (RAIJ, 2011).

A utilização do solo de maneira sustentável, respeitando suas aptidões e limitações ao cultivo, é indispensável para a obtenção de sucesso na prática agrícola. Para garantir o uso racional dos recursos naturais devem-se considerar as classes de solo bem como seus atributos granulométricos e químicos.

Conhecer a distribuição granulométrica de partículas sólidas do solo é fundamental em diversas situações (SILVA et al., 2011). Uma das mais conhecidas é o enquadramento textural que permite separar os solos em diversas classes texturais. A textura, por sua vez, tem grande influência no comportamento físicohídrico e químico do solo (SANTOS et al., 2018).

Dentre as características químicas dos solos, a matéria orgânica do solo (MOS) assume importância fundamental na manutenção de sua qualidade. Essa importância é ainda maior quando se trata de solos de regiões tropicais, geralmente ácidos e de baixa fertilidade natural, onde a capacidade de troca de cátions (CTC), é quase que totalmente proveniente da MOS (SANTOS et al., 2015).

A CTC do solo é um importante parâmetro de fertilidade, todavia pode ser um excelente indicador ambiental pela sua capacidade de reter contaminantes (KASEMODEL et al., 2015). Solos com alta CTC de maneira geral são vistos como indicadores ambientais positivos, enquanto aqueles com baixa, como indicadores negativos. Meurer et al. (2015) explicam que dentre os fatores que afetam a CTC do solo, destacam-se o tipo e a quantidade de argilominerais, teor de MOS e pH da solução do solo.

$\mathrm{O} \mathrm{pH}$ fornece indícios das condições químicas gerais do solo. Solos com acidez elevada (baixos valores de $\mathrm{pH}$ ) geralmente apresentam: baixos teores de bases (cálcio e magnésio principalmente); elevado teor de alumínio tóxico; excesso de manganês; baixa disponibilidade de micronutrientes ( $\mathrm{Mo} \mathrm{e} \mathrm{Cl}$ ) e alta fixação de fósforo nos coloides do solo (RONQUIM, 2010). A variação dos atributos químicos e físicos do solo sob vegetação nativa é menor do que quando se compara com solos de usos agrícolas (CORRÊA et al., 2009). Por isso, a vegetação nativa é um referencial para a avaliação de solos incorporados a sistemas agrícolas. Segundo Silva et al. (2015), os estudos de solos de referência podem fornecer um conjunto de informações valiosas, 
representando um inexplorado potencial para o monitoramento e avaliação da qualidade do solo em diferentes sistemas locais de cultivo e manejo do solo. Por outro lado, um conjunto de informações de referência para solos, permite o estabelecimento de critérios de qualidade ambiental, comumente utilizados por órgãos de monitoramento e controle ambiental.

No Brasil, a criação de bancos de dados de solos ainda é incipiente e sabe-se pouco sobre as áreas de formações vegetais nativas e a fertilidade natural dos solos (SKORUPA et al., 2012; ROCHA et al., 2018). A falta destas informações pode levar a ações inadequadas e insustentáveis, aumentando o risco de degradação ambiental. Diante do exposto, objetivou-se avaliar os atributos de fertilidade dos solos em áreas de vegetação nativa do Estado de MS, visando gerar informações de referência para tomadas de decisões no uso do recurso solo.

\section{MATERIAIS E MÉTODOS}

\section{Área de estudo}

A área de estudo está localizada na porção sul do Estado de Mato Grosso do Sul, entre as

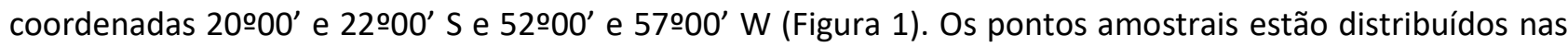
bacias hidrográficas do Rio Paraguai e do Rio Paraná. Na bacia do Rio Paraguai foram coletadas amostras de solo nos municípios de Porto Murtinho, Bonito e Guia Lopes da Laguna e na bacia do Rio Paraná nos municípios de Itaporã, Dourados, Nova Andradina, Taquarussu, Batayporã e Bataguassu.

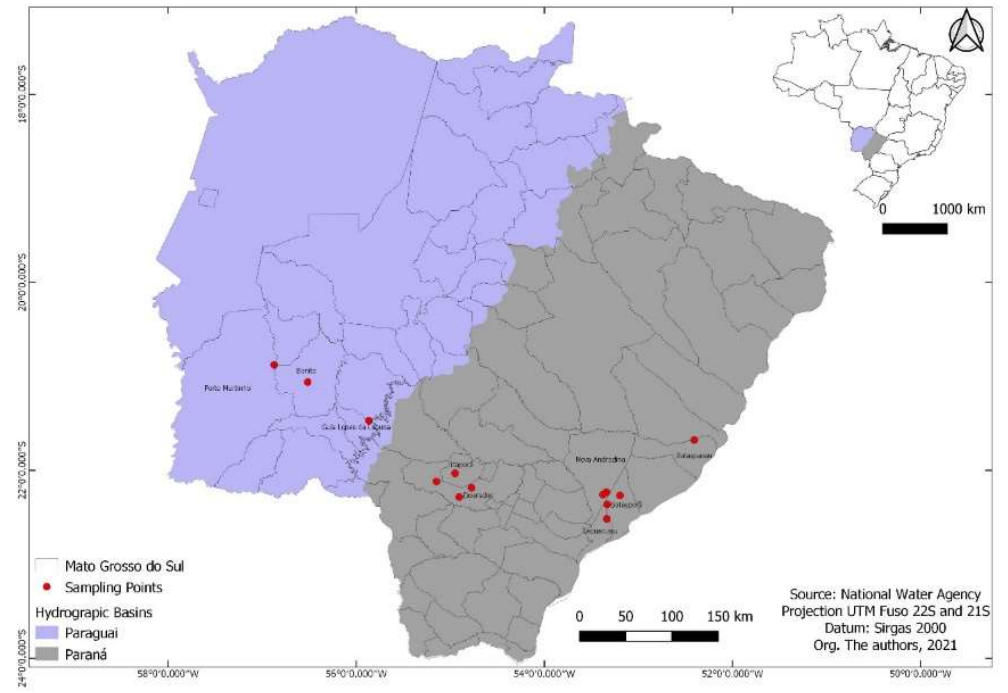

Figura 1: Distribuição dos pontos amostrais no estado de Mato Grosso do Sul.

A extensão geográfica da área de estudo de mais de $500 \mathrm{~km}$ proporciona grande variação nos fatores que atuam na formação do solo, a começar pelas diferenças de material de origem geológica, ígnea, sedimentar e metamórfica (BRASIL, 2006), e outros como precipitação pluviométrica, temperatura, relevo, umidade e vegetação. As amostragens abrangeram solos desenvolvidos sobre três substratos geológicos: a formação Serra Geral na porção Central da área amostrada (Dourados, Itaporã, Guia Lopes da Laguna), formação Caiuá na faixa Leste (Bataguassu, Nova Andradina, Taquarussu e Batayporã) e a formação Bocaína na faixa Oeste (Bonito e Porto Murtinho) (BRASIL, 2006). As classes de solos encontradas foram: Latossolo 
Vermelho (LV), Nitossolo Vermelho (NV), Planossolo Háplico (SX), Argissolo Vermelho-Amarelo (PVA), Chernossolo Rêndzico (MD), Neossolo Regolítico (RR) e Gleissolo Háplico (GX) (SANTOS et al., 2018).

Na faixa Leste da área de estudo (Bataguassu, Nova Andradina, Taquarussu e Batayporã), a geomorfologia é composta por relevo de colinas pouco dissecadas, com vertentes convexas e topos amplos, de morfologia tabular ou alongada e declividade entre 3 e 10\%. Superfícies mais elevadas do que os terrenos adjacentes, pouco dissecadas em forma tabulares ou colinas muito amplas, com declividade entre 2 e $5 \%$ compõem a faixa Central (Dourados, Itaporã, Guia Lopes da Laguna). Na porção Oeste (Bonito e Porto Murtinho), o relevo é composto de morros convexo-côncavos dissecados e topos arredondados ou aguçados. Também se inserem o relevo de topo tabular, característico das chapadas intensamente dissecadas e desfeitas em conjunto de morros de topo plano, a declividade varia entre 15 e 35\% (SEMADE, 2016).

Segundo a classificação de Köppen-Geiger, encontram-se dois tipos climáticos predominantes na área amostrada. Na faixa Leste (Bataguassu, Nova Andradina, Taquarussu e Batayporã) predomina o clima Aw - Clima tropical, com inverno seco. Na Região Central em direção a Oeste (Dourados, Itaporã, Guia Lopes da Laguna, Bonito e Porto Murtinho) predomina o clima Am - Clima tropical úmido ou subúmido (ALVARES et al., 2013). A diversidade geológica, geomorfológica, pedológica e climática condicionou distintas formações vegetais na área de estudo. Em terrenos areníticos lixiviados e ricos em alumínio trocável, ocorrem fitofisionomias de cerrado. Já nos solos de origem ígnea e/ou eruptiva, e logicamente mais férteis, ocorrem os tipos florestais estacionais (IBGE, 2012).

\section{Definição dos pontos amostrais}

Para definição dos pontos de coleta procedeu-se inicialmente com uma consulta espacial por imagens de satélite fornecidas pelo Google Earth Pro, para identificação de fitofisionomias nativas e acessibilidade às áreas. Sequencialmente, foi realizada uma sobreposição das cartas geológicas e pedológicas de Mato Grosso do Sul (BRASIL, 2006). O cruzamento de informações de solos, geologia e vegetação permitiu ter uma ideia preliminar do ambiente de coleta. A partir da exploração espacial da área, foi possível obter as coordenadas geográficas (Tabela 1) e realizar a marcação dos locais de coletas. Foram definidos 13 pontos amostrais em remanescentes de vegetação nativa.

Tabela 1 Classes de solos amostrados e coordenadas geográficas.

\begin{tabular}{lll}
\hline Classes de solo ${ }^{1}$ & Coordenadas Geográficas & \\
\hline Latossolo Vermelho & $53^{\circ} 20^{\prime} 18^{\prime \prime} \mathrm{W}$ & $22^{\circ} 13^{\prime} 54^{\prime \prime} \mathrm{S}$ \\
Latossolo Vermelho & $53^{\circ} 22^{\prime} 34^{\prime \prime} \mathrm{W}$ & $22^{\circ} 15^{\prime} 31^{\prime \prime} \mathrm{S}$ \\
Latossolo Vermelho & $53^{\circ} 20^{\prime} 5^{\prime \prime} \mathrm{W}$ & $22^{\circ} 31^{\prime} 3^{\prime \prime} \mathrm{S}$ \\
Latossolo Vermelho & $53^{\circ} 19^{\prime} 52^{\prime \prime} \mathrm{W}$ & $22^{\circ} 21^{\prime} 48^{\prime \prime} \mathrm{S}$ \\
Nitossolo Vermelho & $53^{\circ} 11^{\prime} 42^{\prime \prime} \mathrm{W}$ & $22^{\circ} 16^{\prime} 8^{\prime \prime} \mathrm{S}$ \\
Planossolo Háplico & $52^{\circ} 24^{\prime} 17^{\prime \prime} \mathrm{W}$ & $21^{\circ} 40^{\prime} 42^{\prime \prime} \mathrm{S}$ \\
Planossolo Háplico & $54^{\circ} 56^{\prime} 59^{\prime \prime} \mathrm{W}$ & $22^{\circ} 1^{\prime} 55^{\prime \prime} \mathrm{S}$ \\
Planossolo Háplico & $54^{\circ} 46^{\prime} 24^{\prime \prime} \mathrm{W}$ & $22^{\circ} 11^{\prime} 12^{\prime \prime} \mathrm{S}$ \\
Argissolo Vermelho-Amarelo & $54^{\circ} 54^{\prime} 20^{\prime \prime} \mathrm{W}$ & $22^{\circ} 16^{\prime} 59^{\prime \prime} \mathrm{S}$ \\
Argissolo Vermelho-Amarelo & $55^{\circ} 8^{\prime} 50^{\prime \prime} \mathrm{W}$ & $22^{\circ} 7^{\prime} 8^{\prime \prime} \mathrm{S}$ \\
Chernossolo Rêndzico & $55^{\circ} 51^{\prime} 56^{\prime \prime} \mathrm{W}$ & $21^{\circ} 28^{\prime} 25 \mathrm{~S}^{\prime \prime}$ \\
Neossolo Regolítico & $56^{\circ} 30^{\prime} 57^{\prime \prime} \mathrm{W}$ & $21^{\circ} 3^{\prime} 41^{\prime \prime} \mathrm{S}$ \\
Gleissolo Háplico & $56^{\circ} 52^{\prime} 18^{\prime \prime} \mathrm{W}$ & $20^{\circ} 52^{\prime} 42^{\prime \prime} \mathrm{S}$ \\
\hline
\end{tabular}

Fonte: ${ }^{1}=$ Santos et al. (2018). 
Para cada ponto amostrado foram obtidas amostras compostas (cinco amostras simples homogeneizadas) de aproximadamente $2 \mathrm{~kg}$ de solo, retiradas com picaretas de aço inoxidável e pá cavadeira isentas de revestimento ou pintura, nas profundidades de 0 a 0,20 e 0,20 a 0,40 m. Foram adotados procedimentos de manuseio, preservação, acondicionamento e transporte de acordo com normas nacionais e internacionais, respeitando-se os prazos de validade, juntamente com as características regionais (CONAMA, 2009).

\section{Análises químicas e granulométricas}

As amostras de solo foram secas ao ar, protegidas de luz solar, destorroadas manualmente e passadas em peneira de aço inoxidável com abertura de $2 \mathrm{~mm}$ para obtenção da terra fina seca ao ar (TFSA) para as determinações químicas e granulométricas.

Todas as variáveis químicas e granulométricas foram determinadas conforme as metodologias descritas por (CLAESSEN, 1997; TEIXEIRA et al., 2017). As variáveis granulométricas (areia, silte e argila), foram determinadas de acordo com o método da pipeta, no qual foi pesado $20 \mathrm{~g}$ de amostra de TFSA, adicionado $250 \mathrm{~mL}$ de água destilada, $10 \mathrm{~mL}$ de hidróxido de sódio $1 \mathrm{~mol} \mathrm{~L}^{-1}$ como agente dispersante.

A determinação do $\mathrm{pH}$ foi feita potenciometricamente na suspensão solo: solução $1: 2,5$ em $\mathrm{CaCl}_{2}$ $0,01 \mathrm{~mol} \mathrm{~L}^{-1}$. A acidez potencial foi estimada pelo uso do pH da solução SMP (mistura de sais neutros com vários tampões). O Ca e o $\mathrm{Mg}$ trocáveis foram extraídas por $\mathrm{KCl} 1 \mathrm{~mol} \mathrm{~L}^{-1}$, em conjunto com o Al trocável, titulando-se numa fração do extrato, o alumínio $\mathrm{com} \mathrm{NaOH}$, na presença de azul-de-bromitol como indicador. Em outra fração, o $\mathrm{Ca}^{+2}$ e o $\mathrm{Mg}^{+2}$ foram determinados por espectrometria de absorção atômica em chama (FAAS).

$\mathrm{O} \mathrm{K}^{+}, \mathrm{P}, \mathrm{Fe}, \mathrm{Mn}, \mathrm{Cu}$ e Zn disponíveis foram extraídos por solução duplo-ácida, composta pela mistura de $\mathrm{H}_{2} \mathrm{SO}_{4}$ 0,05 mol L-1 e $\mathrm{HCl}$ 0,025 mol L-1, conhecida como solução de Mehlich-1. Os teores de $\mathrm{K}^{+}$foram determinados por espectrometria de absorção atômica em chama (FAAS). A determinação de $\mathbf{P}$ disponível foi feita por espectroscopia (UV/Vis), por meio da leitura da intensidade da cor do complexo fosfomolíbdico, produzido pela redução do molibdato com o ácido ascórbico.

$\mathrm{O}$ teor de carbono orgânico (C.O) foi determinado por oxidação com $\mathrm{K}_{2} \mathrm{Cr}_{2} \mathrm{O}_{7}$ em meio sulfúrico, empregando-se como fonte de energia o calor desprendido do $\mathrm{H}_{2} \mathrm{SO}_{4}$ e o aquecimento, método conhecido como Walkley-Black. O excesso de dicromato após a oxidação foi titulado com solução padrão de sulfato ferroso amoniacal e o teor de C.O foi calculado pela quantidade de $\mathrm{Cr}_{2} \mathrm{O}_{7}^{-2}$ reduzido. A soma de bases (SB) foi obtida pela soma dos cátions $\mathrm{Ca}^{+2}, \mathrm{Mg}^{+2}$ e K+. Para a capacidade de troca catiônica a pH 7 (CTC) foi somado a SB + H+Al e a saturação por bases (V\%) foi obtida pela equação: 100.SB/CTC.

\section{Análises estatísticas}

Os dados obtidos foram tratados por meio de medida de posição (média aritmética) e medida de dispersão (desvio padrão). Técnicas estatísticas multivariadas como a análise de componentes principais (ACP), ajudam a interpretar semelhanças ou dissemelhanças do conjunto de dados sem que haja perda 
significativa da informação. Para tal padronizou-se a matriz de dados (média do conjunto de dados transformados igual a 0 e desvio padrão igual a 1), e procedeu-se a análise com os seguintes critérios: 1) valores próprios maiores que um; 2) a variância acumulada é de pelo menos 70\%; 3) cada fator explique pelo menos 5\% da variância (JOLLIFFE, 2002).

\section{RESULTADOS E DISCUSSÃO}

As variáveis granulométricas e químicas determinadas apresentaram grande variabilidade, o que está associada à diversidade de solos encontrada na região de estudo (Tabela 2). A fração granulométrica permitiu classificar os solos em dois grupos texturais, sendo os solos LV, NV e GX da classe muito argilosa e os solos MD, RR, SX e PVA de classe textural média (SANTOS et al., 2018).

De maneira geral, os solos argilosos são mais estáveis comparados aos arenosos quanto ao risco de erosão em condições semelhantes, no entanto, isso não ocorre na prática devido às particularidades de cada classe de solo. Por exemplo, os solos LV e NV do presente estudo estão sobre material de origem semelhante e integram um mesmo grupo textural, muito argiloso, entretanto, o relevo no qual se encontram os solos NV é mais movimentado, e, portanto, há maior risco de erosão se comparado ao solo LV. Nesse sentido, às práticas de manejo devem considerar às particularidades individuais de cada classe de solo e assim evitar problemas como os de erosões de solos.

Tabela 2: Valores médios e desvios padrão das variáveis químicas e granulométricas para os solos estudados.

\begin{tabular}{|c|c|c|c|c|c|c|c|}
\hline $\begin{array}{l}\text { Solos } \\
\text { Variáveis }\end{array}$ & $\mathrm{LV}^{1}$ & $\mathrm{NV}^{1}$ & $\mathrm{RR}^{1}$ & $\begin{array}{l}\mathrm{MD}^{1} \\
0-20 \mathrm{~cm}\end{array}$ & $\mathrm{GX}^{1}$ & $S X^{1}$ & $\mathrm{PVA}^{1}$ \\
\hline Areia $\left(\mathrm{g} \mathrm{kg}^{-1}\right)$ & $198,3 \pm 0,1$ & $217,0 \pm 0,2$ & $446,0 \pm 0,8$ & $364,0 \pm 0,9$ & $285,0 \pm 0,5$ & $638,0 \pm 1,5$ & $571,5 \pm 0,8$ \\
\hline Silte $\left(\mathrm{g} \mathrm{kg}^{-1}\right)$ & $283,3 \pm 0,2$ & $236,0 \pm 0,1$ & $349,0 \pm 0,5$ & $266,0 \pm 0,6$ & $232,0 \pm 0,4$ & $127,5 \pm 0,7$ & $168,0 \pm 0,4$ \\
\hline Argila $\left(\mathrm{g} \mathrm{kg}^{-1}\right)$ & $518,5 \pm 0,6$ & $547,0 \pm 0,7$ & $205,0 \pm 0,5$ & $370,0 \pm 0,3$ & $483,0 \pm 0,8$ & $234,5 \pm 0,1$ & $260,5 \pm 0,2$ \\
\hline $\mathrm{pH}\left(\mathrm{CaCl}_{2}\right)$ & $4,6 \pm 0,01$ & $5,5 \pm 0,01$ & $5,8 \pm 0,01$ & $5,7 \pm 0,01$ & $4,8 \pm 0,03$ & $4,1 \pm 0,07$ & $5,5 \pm 0,06$ \\
\hline $\mathrm{Al}^{3+}\left(\mathrm{cmol}_{\mathrm{c}} \mathrm{dm}^{-3}\right)$ & $1,0 \pm 0,1$ & 0,0 & 0,0 & 0,0 & $0,1 \pm 0,01$ & 1,0 & 0,0 \\
\hline $\mathrm{H}+\mathrm{Al}\left(\mathrm{cmol}_{\mathrm{c}} \mathrm{dm}^{-3}\right)$ & $8,4 \pm 0,2$ & $4,6 \pm 0,1$ & $3,3 \pm 0,1$ & $2,8 \pm 0,1$ & $3,3 \pm 0,1$ & $6,5 \pm 0,2$ & $2,6 \pm 0,1$ \\
\hline $\mathrm{Ca}^{2+}\left(\mathrm{cmol}_{\mathrm{c}} \mathrm{dm}^{-3}\right)$ & $3,8 \pm 0,1$ & $9,3 \pm 0,3$ & $7,9 \pm 0,2$ & $14,7 \pm 0,4$ & $1,8 \pm 0,1$ & $1,1 \pm 0,1$ & $7,3 \pm 0,2$ \\
\hline $\mathrm{Mg}^{2+}\left(\mathrm{cmol}_{\mathrm{c}} \mathrm{dm}^{-3}\right)$ & $1,0 \pm 0,1$ & $4,7 \pm 0,2$ & $4,7 \pm 0,2$ & $3,6 \pm 0,2$ & $0,6 \pm 0,01$ & $0,4 \pm 0,01$ & $3,0 \pm 0,2$ \\
\hline $\mathrm{K}^{+}\left(\mathrm{cmol}_{\mathrm{c}} \mathrm{dm}^{-3}\right)$ & $0,2 \pm 0,01$ & $0,6 \pm 0,01$ & $0,2 \pm 0,01$ & $0,2 \pm 0,01$ & $0,1 \pm 0,01$ & $0,1 \pm 0,01$ & $0,6 \pm 0,01$ \\
\hline $\operatorname{CTC}\left(\mathrm{cmol}_{\mathrm{C}} \mathrm{dm}^{-3}\right)$ & $13,4 \pm 0,2$ & $19,2 \pm 0,3$ & $16,0 \pm 0,3$ & $21,2 \pm 0,3$ & $5,9 \pm 0,1$ & $8,1 \pm 0,1$ & $13,5 \pm 0,2$ \\
\hline $\mathrm{SB}\left(\mathrm{cmol}_{\mathrm{c}} \mathrm{dm}^{-3}\right)$ & $5,0 \pm 0,1$ & $14,6 \pm 0,3$ & $12,7 \pm 0,3$ & $18,4 \pm 0,3$ & $2,5 \pm 0,1$ & $1,5 \pm 0,1$ & $10,9 \pm 0,2$ \\
\hline V (\%) & $37,2 \pm 0,5$ & $75,9 \pm 0,7$ & $79,6 \pm 0,7$ & $86,7 \pm 0,8$ & $43,1 \pm 0,8$ & $21,2 \pm 0,4$ & $76,3 \pm 0,6$ \\
\hline $\mathrm{MO}\left(\mathrm{g} \mathrm{kg}^{-1}\right)$ & $31,7 \pm 0,6$ & $25,2 \pm 0,4$ & $39,9 \pm 0,9$ & $44,7 \pm 0,6$ & $19,7 \pm 0,5$ & $14,3 \pm 0,8$ & $21,4 \pm 0,7$ \\
\hline$P\left(\mathrm{mg} \mathrm{dm}^{-3}\right)$ & $2,7 \pm 0,4$ & $24,2 \pm 0,7$ & $1,0 \pm 0,1$ & $3,2 \pm 0,3$ & $1,8 \pm 0,2$ & $1,8 \pm 0,1$ & $13,6 \pm 0,3$ \\
\hline $\mathrm{S}\left(\mathrm{mg} \mathrm{dm}^{-3}\right)$ & $4,4 \pm 0,1$ & $9,0 \pm 0,5$ & $2,4 \pm 0,3$ & $2,7 \pm 0,2$ & $2,2 \pm 0,2$ & $4,1 \pm 0,1$ & $2,7 \pm 0,1$ \\
\hline $\mathrm{B}\left(\mathrm{mg} \mathrm{dm} \mathrm{m}^{-3}\right)$ & $0,3 \pm 0,01$ & $0,3 \pm 0,01$ & $0,3 \pm 0,01$ & $0,2 \pm 0,01$ & $0,2 \pm 0,01$ & $0,4 \pm 0,01$ & $0,3 \pm 0,01$ \\
\hline $\mathrm{Cu}\left(\mathrm{mg} \mathrm{dm}^{-3}\right)$ & $8,0 \pm 0,1$ & $10,3 \pm 0,2$ & $0,7 \pm 0,1$ & $0,2 \pm 0,1$ & $0,1 \pm 0,1$ & $1,4 \pm 0,1$ & $6,5 \pm 0,2$ \\
\hline $\mathrm{Fe}\left(\mathrm{mg} \mathrm{dm}^{-3}\right)$ & $51,3 \pm 0,8$ & $43,7 \pm 0,9$ & $5,9 \pm 0,2$ & $5,8 \pm 0,3$ & $294,9 \pm 0,9$ & $93,3 \pm 0,4$ & $32,5 \pm 0,1$ \\
\hline $\mathrm{Mn}(\mathrm{mg} \mathrm{dm}-3)$ & $52,0 \pm 0,7$ & $88,5 \pm 0,8$ & $84,3 \pm 0,5$ & $140,8 \pm 0,9$ & $25,2 \pm 0,4$ & $15,1 \pm 0,3$ & $132,0 \pm 0,9$ \\
\hline $\mathrm{Zn}\left(\mathrm{mg} \mathrm{dm}^{-3}\right)$ & $2,4 \pm 0,1$ & $7,7 \pm 0,2$ & $0,9 \pm 0,1$ & $1,1 \pm 0,1$ & $6,6 \pm 0,6$ & $1,1 \pm 0,1$ & $4,8 \pm 0,2$ \\
\hline $\begin{array}{l}\text { Solos } \\
\text { Variáveis }\end{array}$ & $\mathrm{LV}^{1}$ & $\mathrm{NV}^{1}$ & $\mathrm{RR}^{1}$ & $\begin{array}{l}\mathrm{MD}^{1} \\
20-40 \mathrm{~cm}\end{array}$ & $\mathrm{GX}^{1}$ & $S X^{1}$ & $\mathrm{PVA}^{1}$ \\
\hline Areia $\left(\mathrm{g} \mathrm{kg}^{-1}\right)$ & $187,8 \pm 0,4$ & $213,0 \pm 0,3$ & $484,0 \pm 0,6$ & $367,0 \pm 0,3$ & $330,0 \pm 0,4$ & $672,0 \pm 0,9$ & $516,5 \pm 0,8$ \\
\hline Silte $\left(\mathrm{g} \mathrm{kg}^{-1}\right)$ & $187,5 \pm 0,3$ & $109,0 \pm 0,4$ & $351,0 \pm 0,2$ & $323,0 \pm 0,5$ & $45,0 \pm 0,1$ & $141,5 \pm 0,2$ & $172,0 \pm 0,2$ \\
\hline Argila $\left(\mathrm{g} \mathrm{kg}^{-1}\right)$ & $624,8 \pm 0,9$ & $678,0 \pm 0,8$ & $165,0 \pm 0,3$ & $310,0 \pm 0,2$ & $625,0 \pm 0,6$ & $186,5 \pm 0,1$ & $311,5 \pm 0,2$ \\
\hline $\mathrm{pH}\left(\mathrm{CaCl}_{2}\right)$ & $4,5 \pm 0,1$ & $5,6 \pm 0,2$ & $5,5 \pm 0,2$ & $6,3 \pm 0,1$ & $4,8 \pm 0,1$ & $4,0 \pm 0,1$ & $5,4 \pm 0,1$ \\
\hline $\mathrm{Al}^{3+}\left(\mathrm{cmol}_{\mathrm{c}} \mathrm{dm}^{-3}\right)$ & $1,2 \pm 0,1$ & 0,0 & 0,0 & 0,0 & $0,2 \pm 0,1$ & $1,1 \pm 0,1$ & 0,0 \\
\hline $\mathrm{H}+\mathrm{Al}\left(\mathrm{cmol}_{\mathrm{c}} \mathrm{dm}^{-3}\right)$ & $6,7 \pm 0,2$ & $3,9 \pm 0,2$ & $3,4 \pm 0,2$ & $2,0 \pm 0,2$ & $9,0 \pm 0,3$ & $7,6 \pm 0,4$ & $2,9 \pm 0,1$ \\
\hline $\mathrm{Ca}^{2+}\left(\mathrm{cmol}_{\mathrm{C}} \mathrm{dm}^{-3}\right)$ & $2,7 \pm 0,1$ & $9,2 \pm 0,2$ & $5,4 \pm 0,2$ & $15,5 \pm 0,3$ & $5,0 \pm 0,1$ & $0,7 \pm 0,1$ & $6,6 \pm 0,1$ \\
\hline $\mathrm{Mg}^{2+}\left(\mathrm{cmol}_{\mathrm{c}} \mathrm{dm}^{-3}\right)$ & $0,7 \pm 0,01$ & $4,3 \pm 0,1$ & $3,8 \pm 0,1$ & $3,5 \pm 0,1$ & $2,4 \pm 0,1$ & $0,2 \pm 0,01$ & $2,9 \pm 0,1$ \\
\hline $\mathrm{K}^{+}\left(\mathrm{cmol}_{\mathrm{c}} \mathrm{dm}^{-3}\right)$ & $0,1 \pm 0,01$ & $0,2 \pm 0,01$ & $0,1 \pm 0,01$ & $0,1 \pm 0,01$ & $0,1 \pm 0,01$ & $0,1 \pm 0,01$ & $0,4 \pm 0,01$ \\
\hline $\mathrm{CTC}\left(\mathrm{cmol}_{\mathrm{C}} \mathrm{dm}^{-3}\right)$ & $10,2 \pm 0,1$ & $17,8 \pm 0,2$ & $12,7 \pm 0,2$ & $21,1 \pm 0,3$ & $16,5 \pm 0,2$ & $8,6 \pm 0,1$ & $12,9 \pm 0,4$ \\
\hline
\end{tabular}




\begin{tabular}{|c|c|c|c|c|c|c|c|}
\hline $\mathrm{SB}\left(\mathrm{cmol}_{\mathrm{c}} \mathrm{dm}^{-3}\right)$ & $3,5 \pm 0,1$ & $13,9 \pm 0,3$ & $9,3 \pm 0,1$ & $19,1 \pm 0,2$ & $7,5 \pm 0,1$ & $1,0 \pm 0,1$ & $10,0 \pm 0,2$ \\
\hline V (\%) & $37,1 \pm 0,4$ & $78,3 \pm 0,7$ & $73,3 \pm 0,8$ & $90,3 \pm 0,9$ & $45,3 \pm 0,6$ & $14,1 \pm 0,4$ & $73,2 \pm 0,9$ \\
\hline $\mathrm{MO}\left(\mathrm{g} \mathrm{kg}^{-1}\right)$ & $21,1 \pm 0,4$ & $21,9 \pm 0,3$ & $27,4 \pm 0,5$ & $39,4 \pm 0,4$ & $33,9 \pm 0,8$ & $18,8 \pm 0,7$ & $14,4 \pm 0,2$ \\
\hline \multicolumn{8}{|l|}{... continuação } \\
\hline $\mathrm{P}\left(\mathrm{mg} \mathrm{dm} \mathrm{m}^{-3}\right)$ & $1,9 \pm 0,1$ & $4,0 \pm 0,2$ & $0,2 \pm 0,01$ & $1,5 \pm 0,1$ & $9,8 \pm 0,1$ & $1,7 \pm 0,1$ & $8,4 \pm 0,1$ \\
\hline $\mathrm{S}\left(\mathrm{mg} \mathrm{dm} \mathrm{m}^{-3}\right)$ & $5,0 \pm 0,1$ & $6,9 \pm 0,1$ & $2,5 \pm 0,1$ & $2,6 \pm 0,1$ & $2,5 \pm 0,1$ & $6,5 \pm 0,1$ & $2,8 \pm 0,1$ \\
\hline$B\left(\mathrm{mg} \mathrm{dm}^{-3}\right)$ & $0,3 \pm 0,01$ & $0,2 \pm 0,01$ & $0,2 \pm 0,01$ & $0,2 \pm 0,01$ & $0,3 \pm 0,01$ & $0,3 \pm 0,01$ & $0,2 \pm 0,01$ \\
\hline $\mathrm{Cu}\left(\mathrm{mg} \mathrm{dm} \mathrm{m}^{-3}\right)$ & $9,3 \pm 0,1$ & $12,8 \pm 0,3$ & $0,5 \pm 0,01$ & $0,8 \pm 0,01$ & $10,7 \pm 0,1$ & $0,4 \pm 0,1$ & $8,7 \pm 0,4$ \\
\hline $\mathrm{Fe}\left(\mathrm{mg} \mathrm{dm}^{-3}\right)$ & $53,4 \pm 0,4$ & $60,9 \pm 0,5$ & $7,8 \pm 0,3$ & $5,2 \pm 0,2$ & $112,8 \pm 0,8$ & $100,1 \pm 0,9$ & $23,5 \pm 0,6$ \\
\hline $\mathrm{Mn}\left(\mathrm{mg} \mathrm{dm}{ }^{-3}\right)$ & $38,1 \pm 0,2$ & $78,6 \pm 0,5$ & $62,5 \pm 0,2$ & $118,5 \pm 0,7$ & $13,0 \pm 0,2$ & $10,4 \pm 0,2$ & $106,5 \pm 0,4$ \\
\hline $\mathrm{Zn}\left(\mathrm{mg} \mathrm{dm}^{-3}\right)$ & $2,4 \pm 0,1$ & $6,8 \pm 0,1$ & $0,8 \pm 0,1$ & $1,0 \pm 0,1$ & $8,0 \pm 0,1$ & $0,9 \pm 0,1$ & $3,0 \pm 0,1$ \\
\hline
\end{tabular}

$\mathrm{LV}=$ Latossolo Vermelho; NV = Nitossolo Vermelho; RR = Neossolo Regolítico; MD = Chernossolo Rêndzico; GX = Gleissolo Háplico; SX = Planossolo Háplico; PVA = Argissolo Vermelho-Amarelo; MO = Matéria Orgânica; CTC = Capacidade de Troca Catiônica; SB = Soma de Bases; H+Al = Acidez Potencial; V\% = Saturação por Bases; \pm = desvio padrão; Fonte: ${ }^{1}=$ Santos et al. (2018).

Com relação ao risco de erosão observou-se um aumento no teor de argila em profundidade de $20 \%$ e $30 \%$ para os solos PVA e NV, respectivamente. Considerando a declividade da área e o contraste textural o risco de erosão pode ser considerado alto quando não adotadas práticas adequadas de manejo. Para ambientes com essas características, a evolução da agropecuária brasileira tem apresentado novos modelos de produção, ao incorporar os princípios da agricultura conservacionista, como sistema de plantio direto, integração lavoura pecuária, integração lavoura pecuária floresta e sistemas agroflorestais, que possibilitam o uso sustentável da terra e permitem o uso eficiente dos recursos locais disponíveis (BALBINO et al., 2011; DONAGEMMA et al., 2016; FERNANDES et al., 2019).

Todas as classes de solo analisadas apresentaram características ácidas, com pequena variação no valor de $\mathrm{pH}\left(\mathrm{CaCl}_{2}\right)$ nas camadas analisadas. Com relação aos limites de interpretação adotados por Souza et al. (2004), em amostras de solos do Cerrado na camada de 0 a $20 \mathrm{~cm}$, o pH $\left(\mathrm{CaCl}_{2}\right)$ dos solos RR e MD é considerado alto, médio para os solos LV e GX, adequado para os solos NV e PVA e baixo para o solo SX.

Em termos de valores os solos SX, LV e GX apresentaram pH $\left(\mathrm{CaCl}_{2}\right)$ abaixo de 5,0 nas duas camadas analisadas. Condição que indica haver a presença de $\mathrm{Al}^{3+}$ na solução do solo. Segundo Kochian et al. (2015) em solos onde o pH $\left(\mathrm{CaCl}_{2}\right)$ é inferior a 5,0 a acidez pode estar associada ao $\mathrm{Al}^{3+}$ devido ao aumento de sua solubilidade. Essa condição pode ser confirmada observando a concentração média de $\mathrm{Al}^{3+}$ nos solos SX, LV e GX.

Com exceção dos solos SX, LV e GX que apresentaram na camada superficial teor de $\mathrm{Al}^{3+}$ de 1,$0 ; 1,0$ e $0,1 \mathrm{cmol}_{\mathrm{c}} \mathrm{dm}^{-3}$ respectivamente, nos demais solos o $\mathrm{Al}^{3+}$ não foi detectado. Condição justificada pela alta saturação por bases encontrada nesses solos, e por consequência disso baixa acidez. À medida que se eleva o pH da solução do solo, as moléculas de água da esfera de hidratação perdem $\mathrm{H}^{+}$(hidrólise do Al) até o ponto de equilíbrio que ocorre em torno de $\mathrm{pH} 5,0$, em que a atividade das formas de $\mathrm{Al}$ na solução $\left[\mathrm{Al}^{3+}\right.$, $\left.\mathrm{AlOH}^{2+}, \mathrm{Al}(\mathrm{OH})_{2}{ }^{+}\right]$se equivalem (CAMPOS et al., 2014).

Os maiores teores de $\mathrm{H}+\mathrm{Al}$ foram encontrados nos solos LV, SX e GX, corroborando com os teores de $\mathrm{Al}^{3+}$ desses solos. A relação existente entre $\mathrm{H}+\mathrm{Al}$ e $\mathrm{Al}^{3+}$ decorre da decomposição de minerais de argila, no qual ocorre liberação do $\mathrm{Al}^{+3}$ das camadas octaédricas. $\mathrm{O} \mathrm{Al}^{+3}$ assim produzido pode permanecer na superfície em forma trocável (deslocando $\mathrm{H}^{+}$dos sítios de adsorção do solo) ou passar para a solução do solo 
(RONQUIM, 2010).

Teores de $\mathrm{H}+\mathrm{Al}$ entre 2 e 4,6 $\mathrm{cmol}_{\mathrm{c}} \mathrm{dm}^{-3}$ foram encontrados em todas as amostras de solo $\mathrm{NV}, \mathrm{RR}$, MD e PVA, o que pode estar associado ao alto poder de tamponamento dos teores de MO especialmente nos solos MD e RR. Por outro lado, a presença de minerais básicos originários de rochas ricas em cálcio e magnésio especialmente no solo MD pode justificar o menor teor de $\mathrm{H}+\mathrm{Al}$ encontrado nas duas camadas desse solo.

Em relação ao $\mathrm{Ca}^{2+}$, na camada superficial houve predomínio de teores altos para os solos $\mathrm{MD}, \mathrm{RR}$, NV e PVA, adequado para os solos LV e GX e baixo para os solos SX (SOUZA et al., 2004). A manutenção do $\mathrm{Ca}^{2+}$ no solo é função do material de origem (rocha), sendo influenciado pela sua textura, teor de matéria orgânica e pela remoção das plantas. Verificou-se que nos solos com teor alto de $\mathrm{Ca}^{2+}$ os teores de matéria orgânica também são altos, o que aponta para importância da matéria orgânica do solo na manutenção desse nutriente. Por outro lado, isso se deve ao material parental que originou solos férteis e a integração harmoniosa dos ciclos biogeoquímicos em ecossistemas naturais.

Das sete classes de solos analisadas duas (MD e GX), apresentaram maior teor de $\mathrm{Ca}^{2+}$ na camada subsuperficial. As justificativas para esses resultados são distintas em função desses solos serem de classes e material de origem diferentes. Para o solo MD, a justificativa consiste no material de origem rico em calcário, presente na região da Serra da Bodoquena (PEREIRA et al., 2013). Por outro lado, no solo GX os teores de $\mathrm{Ca}^{2+}$ estão associadas as características naturais e a composição dos sedimentos trazidos em suspensão e depositados sobre essas áreas, uma vez que são formados nas proximidades dos cursos d'água sujeitos a condições de hidromorfia. $\mathrm{O}$ aumento gradativo nos teores $\mathrm{Ce}^{\mathrm{Ca}}{ }^{2+}$ em profundidade indica a presença de diferentes níveis de hidromorfismo no ambiente. A hidrodinâmica desse solo favorece o aporte de nutrientes na camada subsuperficial em função da passagem vertical de água no perfil do solo (CORINGA et al., 2012).

Com exceção do solo $\mathrm{GX}$ todos os demais apresentaram maior teor de $\mathrm{Mg}^{2+}$ na camada superficial. $\mathrm{O}$ teor de $\mathrm{Mg}^{2+}$ encontrado na camada subsuperficial do solo GX foi quatro vezes superior ao encontrado na camada superficial. Esse resultado pode ser justificado pela forte influência da passagem vertical de água no perfil desse solo. Em relação as faixas de interpretação para o teor de $\mathrm{Mg}^{2+}$ na camada superficial os solos NV, RR, MD e PVA são considerados altos, LV e GX considerados adequados e SX considerado baixo (SOUZA et al., 2004). As faixas de interpretação dos teores de $\mathrm{Mg}^{2+}$ apresentaram tendências semelhantes ao $\mathrm{Ca}^{2+}, \mathrm{o}$ que pode ser justificado pela origem e ao comportamento químico desses cátions nos minerais e matéria orgânica do solo.

A inter-relação entre os nutrientes $\mathrm{Ca}^{2+}$ e $\mathrm{Mg}^{2+}$ é de fundamental importância na nutrição vegetal, devido às suas propriedades químicas próximas, como o raio iônico, valência, grau de hidratação e mobilidade, fazendo com que haja competição pelos sítios de adsorção no solo, e na absorção pelas raízes (MEDEIROS et al., 2008). Como consequência, a presença de um pode prejudicar os processos de adsorção e absorção do outro (FONSECA et al., 2018).

Relações entre Ca:Mg no solo e na planta tem sido estabelecida em busca de equilíbrio e maiores 
produtividades. Nos solos analisados em condição de mata nativa a relação Ca:Mg na camada superficial foi de 3,8; 1,9; 1,6; 4; 3; 2,7; 2,4 para os solos LV; NV; RR; MD; GX; SX e PVA, respectivamente. Em relação aos limites de interpretação da relação Ca:Mg os solos LV, MD, GX, SX e PVA apresentaram relação adequada, NV e RR apresentam relação considerada estreita (SOUZA et al., 2004). Medeiros et al. (2008) considera relações Ca:Mg entre 4:1 a 8:1 como adequadas para culturas agricultáveis. Entretanto, Silva et al. (2012) verificaram que a relação $\mathrm{Ca}: \mathrm{Mg}$ de 1:1 proporcionou a maior produção de matéria seca da parte aérea da soja em um Argissolo Vermelho-Amarelo distrófico. Todavia em um sistema natural o balanceamento dos nutrientes no solo se dá por meio dos ciclos biogeoquímicos.

Com exceção dos solos GX e SX que mantiveram teores de $\mathrm{K}^{+}$de $0,1 \mathrm{cmol}_{\mathrm{c}} \mathrm{dm}^{-3}$ para as duas camadas analisadas, nos demais solos os teores de $\mathrm{K}^{+}$foram sempre maiores na camada superficial, o que pode ser justificado dentre outros fatores, à deposição de material orgânico, que se acumula no horizonte superficial das áreas de matas nativas preservadas, liberando nutrientes como o $\mathrm{K}^{+}$no processo de mineralização (BOCARDI et al., 2018).

$\mathrm{Na}$ camada superficial os teores de $\mathrm{K}^{+}$são considerados altos para os solos NV e PVA, adequado para os solos LV, RR e MD, e médio para os solos GX e SX (SOUZA et al., 2004). Os menores teores de $\mathrm{K}^{+}$ encontrados nos solos GX e SX, comparado aos demais solos analisados possivelmente estejam associados a perdas por lixiviação devido a solubilidade e mobilidade do íon $\mathrm{K}^{+}$no perfil do solo. Outro fator a ser considerado no solo SX é a sua textura, com teor de areia acima de $60 \%$, essa condição favorece maior intensidade de lixiviação comparada a solos argilosos como LV e NV do presente estudo (WERLE et al., 2008). Esses valores são importantes, pois indicam a fertilidade natural dos solos e suas respectivas potencialidades agrícolas.

Conforme os limites de interpretação adotados por Souza et al. (2004), a CTC média dos solos analisados na camada superficial apresentam-se na seguinte ordem: alta para os solos NV, RR, MD e PVA, adequada para os solos LV e SX e baixa para o solo GX. A CTC, SB e V\%, são variáveis diretamente envolvidas na fertilidade dos solos. Considerando essas variáveis pode-se evidenciar alta fertilidade natural nos solos MD, NV, RR e PVA, e baixa fertilidade para os solos SX, LV e GX evidenciados pelos baixos valores de saturação por bases. A baixa fertilidade dos solos SX, LV e GX está associada às concentrações de cátions ácidos $\mathrm{Al}^{3+} \mathrm{e}$ $\mathrm{H}+\mathrm{Al}^{+}$que foram maiores nesses solos, expressando consequentemente valores baixos de $\mathrm{pH}$, indicando toxidez por alumínio, valores de $\mathrm{pH}<5,0$ (SILVA et al., 2018).

Para neutralização do $\mathrm{Al}^{3+}$ e elevação do $\mathrm{pH}$ do solo a níveis ideais para a maioria das culturas na região do Cerrado a calagem tem sido uma das práticas mais utilizada, pois minimiza acidez e aumenta a capacidade de elementos básicos presentes no solo (LEITE et al., 2018). Por outro lado, sistemas de manejo que preconizam níveis adequados de $\mathrm{MO}$ no solo contribuem para redução dos níveis de $\mathrm{Al}^{3+}$, devido a formação de complexos Al-MO. A interação entre o Al e MO é uma das reações que mais influencia as propriedades dos solos ácidos (ZAMBROSI et al., 2007).

Os teores de MO foram classificados como muito baixo para NV, GX e SX, médio para LV e PVA e alto para os solos MD e RR (SOUSA et al., 2004). Em termos de valores os maiores teores foram encontrados na 
camada superficial, nos solos MD e RR, com valores médios de 44,7 e 39,9 $\mathrm{g} \mathrm{kg}^{-1}$, respectivamente.

Em relação as camadas do solo, exceto o GX e SX, todos os demais solos analisados apresentaram teores decrescentes de $\mathrm{MO}$ em profundidade, fato este também observados em outros estudos (COSTA et al., 2017; FREITAS et al., 2018), onde atribuem este padrão em função da maior deposição de matéria orgânica em superfície, que é intensificada devido ao aporte de resíduos vegetais e, também, devido à ausência de influência antrópica.

Os altos teores de MO encontrados nos solos MD e RR coincidem com os maiores valores de CTC, mostrando a importância da MO como condicionador de cargas em solos de textura média. $\mathrm{O}$ teor de matéria orgânica assume importante papel na manutenção de ambientes não fertilizados. Portanto, práticas que favoreçam ou incrementem os teores de MO devem ser estimuladas. Os teores médios de $\mathrm{P}$ na camada

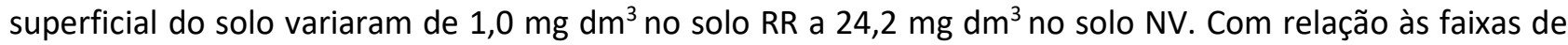
interpretação dos valores médios para a camada superficial do solo houve predomínio de teores muito baixo para os solos: LV, RR, SX e GX; baixo para MD; médio para o PVA e alto para o NV (SOUSA et al., 2004).

Com exceção do solo GX, todos os demais apresentaram menores teores de P na camada de 20 a 40 $\mathrm{cm}$, fato que aponta para uma possível contribuição da MO na disponibilização deste elemento. Segundo (FELIX et al., 2016) os ácidos húmicos e fúlvicos contidos na MO tendem a reduzir a adsorção de $\mathrm{P}$ no solo, por meio da competição pelos sítios de troca aniônica, aumentando o P disponível para solução do solo.

Os nutrientes S e B apresentaram pequena variação nas camadas analisadas. Em média os maiores teores de S e B foram encontrados na camada de 0 a $20 \mathrm{~cm}$ dos solos NV e SX, com valores de 9,0 e 0,4 mg $\mathrm{dm}^{3}$, respectivamente. Com exceção do solo NV, todos os demais solos analisados na camada de 0 a $20 \mathrm{~cm}$ apresentaram teores de $\mathrm{S}$ menor que $5 \mathrm{mg} \mathrm{dm}^{3}$, valores classificados como baixos para os solos de Cerrado (SOUSA et al., 2004). Os baixos teores de S estão associados a pobreza do material de origem nesse elemento e possíveis perdas por lixiviação. Broch et al. (2011), trabalharam em um experimento na região de Maracajú, Mato Grosso do Sul, em um Latossolo Vermelho Distroférrico de textura argilosa, no qual foi detectado deslocamento de S no perfil do solo.

De maneira geral, os teores de Cu foram maiores na camada subsuperficial, excetuando-se os solos RR e SX, que apresentaram teores mais altos na camada de 0 a $20 \mathrm{~cm}$. Os solos LV, NV e PVA apresentaram os maiores teores de $\mathrm{Cu}$ dentre todos os solos analisados. Os menores teores de $\mathrm{Cu} 0,1$ e 0,2 $\mathrm{mg} \mathrm{dm}^{3}$, foram observados na camada de 0 a $20 \mathrm{~cm}$ dos solos GX e MD, respectivamente. Conforme as classes de interpretação para solos do Cerrado têm-se que os teores de $\mathrm{Cu}$ na camada de 0 a $20 \mathrm{~cm}$ são altos para as classes de solo: LV, NV, SX e PVA, médio para o solo RR e baixo para os solos MD e GX (SOUSA et al., 2004).

Os maiores teores de Fe foram encontrados na camada subsuperficial dos solos GX e SX, com valores médios de 112,8 e 100,1 mg dm 3 , respectivamente. Os teores mais elevados em profundidade mostra uma distribuição geoquímica esperada para esse elemento, visto que, são solos que apresentam horizonte subsuperfical de coloração acinzentada, com mosqueados amarelados ou avermelhados, oriundos da oxidação do ferro na matriz do solo, em consequência dos fenômenos de oxirredução, favorecidas pelas condições de hidromorfismo, características desses solos (BIONDI et al., 2011), onde o Fe torna-se bastante 
solúvel e passível de ser lixiviado para subsuperfície, corroborando com os teores mais altos encontrados (CASSOL et al., 2018).

Os teores de $\mathrm{Mn}$ e $\mathrm{Zn}$ foram maiores na camada superficial para todos os solos analisados, comportamento semelhante foi observado por Moline et al. (2015) que atribuiu ao efeito da matéria orgânica na retenção desses elementos. De maneira geral, o Zn é relatado como sendo um dos micronutriente mais limitantes para o desenvolvimento das plantas, por expressar baixos teores nos solos naturais do Cerrado (FAQUIN, 2005; OLIVEIRA et al., 2017). No entanto, nem todos os solos sob Cerrado apresentam baixos teores de $\mathrm{Zn}$. Por exemplo, das sete classes de solos analisadas no presente estudo quatro (LV, NV, GX e PVA), apresentaram teores considerados altos (SOUZA et al., 2004). Por outro lado, solos como RR, MD e SX mostraram teores em torno de $1 \mathrm{mg} \mathrm{dm}^{3}$ valor considerado baixo.

\section{Análise de componentes principais}

A análise de componentes principais foi realizada para as profundidades de 0 a 0,20 e 0,20 a 0,40 m, com o objetivo de observar semelhanças ou diferenças entre as camadas de solo estudadas, bem como entre as classes de solos. Para reduzir a dimensionalidade, a matriz de dados foi padronizada (média do conjunto de dados transformados igual a 0 e desvio padrão igual a 1), e para seleção das componentes principais (CP) utilizou-se o critério de Kaiser que sugere o uso de CP com valores próprios maiores do que a unidade ( $\lambda i>$ 1) (KAISER, 1958; HONGYU et al., 2015). Assim, foram retidas as duas primeiras CP, as quais explicaram 71,55 \% da variância dos dados, sendo 47,86\% da variância explicada pela CP1 e 23,69\% pela CP2 (Figura 2).

As variáveis que melhor explicaram as proporções de variâncias e apresentaram correlação com a $\mathrm{CP} 1$ foram: $\mathrm{pH}, \mathrm{Ca}^{2+}, \mathrm{Mg}^{2+}, \mathrm{SB}, \mathrm{CTC}, \mathrm{V} \%$ e Zn, $\mathrm{Al}^{3+}$ e H+Al. A CP2 apresentou maior associação com as variáveis $\mathrm{S}$, Cu e argila (Figura $2 \mathrm{~A}$ ).
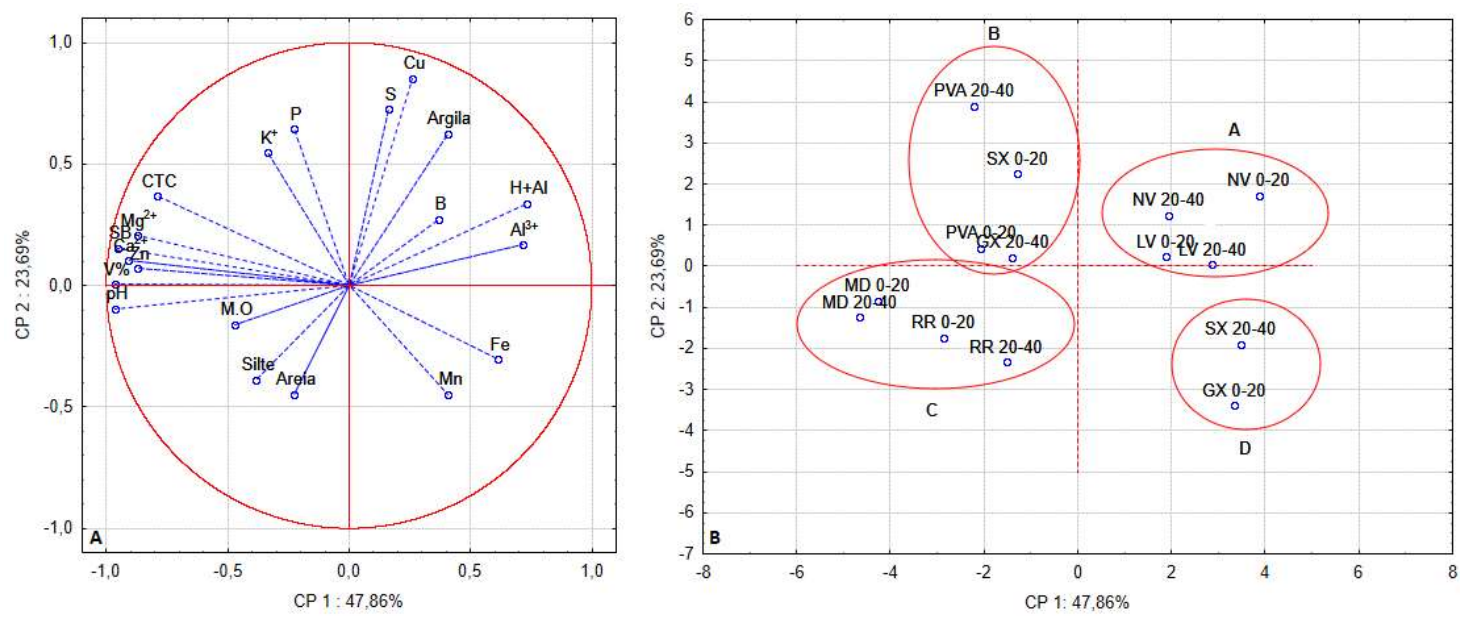

Figura 2: $\mathbf{A}=$ Diagrama de ordenação obtido pela análise de componentes principais mostrando a projeção das variáveis no plano do fator CP1 × CP2. B = diagrama de projeção das classes de solos em função de suas variáveis no plano do fator CP1 X CP2. MO = matéria orgânica; $\mathrm{CTC}=$ Capacidade de troca catiônica a pH 7,0; V\% = saturação por bases; $\mathrm{H}+\mathrm{Al}=$ acidez potencial. $\mathrm{LV}=$ Latossolo Vermelho; $\mathrm{NV}=$ Nitossolo Vermelho; $\mathrm{RR}=$ Neossolo Regolítico; $\mathrm{MD}=$

Chernossolo Rêndzico; GX = Gleissolo Háplico; SX = Planossolo Háplico; PVA = Argissolo Vermelho-Amarelo.

A representação gráfica biplot (entre CP1 e CP2) (Figura 2B) permitiu caracterizar as variáveis químicas que mais discriminaram na formação de quatro agrupamentos, indicando assim inicialmente a 
ampla variabilidade que existe nestes ambientes. As variáveis $\mathrm{SB}, \mathrm{Ca}^{2+}, \mathrm{Mg}^{2+}, \mathrm{Zn}, \mathrm{V} \%, \mathrm{CTC}$ e $\mathrm{pH}\left(\mathrm{CaCl}_{2}\right)$ apresentaram contribuições similares para o eixo negativo da CP1, e são altamente correlacionadas entre si, isto foi verificado pelas variáveis que têm vetor de maior comprimento e que foram mais próximas ao eixo negativo da CP1 (Figura 2A). Essa componente pode ser denominada como sendo de alta fertilidade representada pelos solos MD e RR. As características que unem esses dois solos no terceiro quadrante são: Altos teores de $\mathrm{MO}, \mathrm{Ca}^{2+}$ e $\mathrm{Mg}^{2+}$. Por outro lado, a mineralogia calcária do solo MD (PEREIRA et al., 2013), os teores de silte do solo RR e os teores de MO encontrados nos solos RR e MD discriminaram este grupo de solo dos demais (Figura 2B).

Apesar da boa fertilidade química, solos como RR e MD possuem algumas limitações físicas como pequena profundidade que impede uma boa retenção e infiltração de água, alta suscetibilidade à erosão, não possibilitando condições para um bom desenvolvimento radicular, consistindo em solos limitantes principalmente para culturas perenes (GONÇALVES et al., 2013).

As variáveis $\mathrm{Al}^{3+}$ e $\mathrm{H}+\mathrm{Al}$ são correlacionadas entre si, e inversamente correlacionadas aos índices de fertilidade e pH do solo (Figura $1 \mathrm{~A}$ ). Essa componente (eixo positivo de $\mathrm{X}$ ), expressa solos de baixa fertilidade como o LV, SX e GX, que apresentaram baixos valores de saturação por bases e acidez elevada, indicando toxidez por alumínio (SILVA et al., 2018). Apesar da baixa fertilidade natural, característica da região do Cerrado Costa et al. (2018), o LV pode ser altamente produtivo, desde que se faça a neutralização da acidez, com aplicação de calcário e adição de quantidades adequadas de nutrientes, além de utilizarem práticas que favoreçam ou incrementem os teores de M.O nos solos. Já os solos SX e GX em função do caráter hidromórfico, a drenagem imperfeita, a opção mais adequada é deixar como áreas de preservação da fauna e flora e de mananciais hídricos.

As variáveis $\mathrm{S}$, $\mathrm{Cu}$ e argila são correlacionadas entre si, e estão próximas ao eixo positivo da $\mathrm{CP} 2$, no primeiro quadrante (Figura 2A). No gráfico de escores (Figura 2B), é possível observar que no primeiro quadrante ficaram agrupados os solos NV e LV, indicando que esses solos se diferem dos demais especialmente em função dos teores de S, Cu e argila.

A correlação positiva Cu aos teores de argila no primeiro quadrante (Figura-1A), indica que em grande parte esse micronutriente provém da fração argila, o que é coerente com o material parental dos solos LV e NV, provenientes da formação Serra Geral constituída por rochas ígneas como basalto e basalto adensito, que são naturalmente ricos em micronutrientes (BRASIL, 2006; PAYE et al., 2010).

Com relação as classes de solos e as camadas analisadas é possível evidenciar com base nos escores (Figura 2B), que os solos dos grupos B e D (GX, SX e PVA), foram os que mais se diferenciaram entre as camadas. Esse fato pode ser justificado pelos processos pedogenéticos que ocorrem nesses solos. Por exemplo, os solos PVA e SX passam por processos de destruição de argila com formação de horizonte B textural (ferrólise), já o solo GX passa por processos redução de Fe em condições anaeróbias e translocação formando horizontes acinzentados com ou sem mosqueado denominado gleização (SANTOS et al., 2018). Essas características inerentes a esses solos são possíveis justificativas para a separação dessas classes de solos das demais, ou mesma entre si pelas duas profundidades, como ocorreu com os solos GX e SX. 
De maneira geral, com a aplicação da ACP foi possível observar relações entre variáveis, camadas e classes de solos analisados. Por se tratar de solos de referência essas relações são atribuídas ao material parental e processos pedogenéticos. Em função dessa variabilidade, destacam expressivas diferenciações de solos. É importante salientar que as informações obtidas neste estudo, são de fundamental importância para serem usadas como um critério de comparação em programas de controle e monitoramento ambiental, pois, de modo geral, as variáveis analisadas no presente estudo estão entre as mais influenciadas pelos usos atuais da terra na região dessa pesquisa. De acordo com a situação descrita pela $A C P$, a ocupação dos solos pela agricultura ou outras atividades devem ser orientados para evitar a degradação e promover a qualidade física, química e biológica dos solos.

\section{CONCLUSÕES}

A fertilidade dos solos sob remanescentes de vegetação nativa está intimamente ligada ao material parental e aos processos pedogenéticos. Os solos MD, NV, RR e PVA apresentam alta fertilidade natural evidenciados pelos altos valores de CTC, SB e V\%. A baixa fertilidade natural dos solos SX, LV e GX está associada aos altos teores de $\mathrm{Al}^{3+}$ e $\mathrm{H}+\mathrm{Al}^{+}$e valores baixos de $\mathrm{pH}$ e $\mathrm{V} \%$.

Os solos LV e NV por possuírem maiores teores de argila podem contribuir com maior capacidade de retenção de água e fornecimento de nutrientes favoráveis ao desenvolvimento de plantas. Os solos GX e SX por possuírem características químicas indesejáveis para atender à demanda das plantas, como baixos teores de nutrientes e acidez elevada, localizam próximos as nascentes e aos cursos d'água, por isso devem deixálos como áreas de preservação da fauna e flora e de mananciais hídricos. Os solos RR e MD esses apresentam limitações ao uso agrícola como pequena profundidade que impede uma boa retenção e infiltração de água, dificuldade de mecanização e risco à erosão.

O conhecimento dos atributos de fertilidade do solo é importante para manejo adequado, tanto para a manutenção da vegetação nativa, quanto para maior aproveitamento do solo em determinado uso, resultando em economia ao homem e a própria natureza, evitando tomadas de decisões errôneas na utilização dos recursos naturais.

\section{REFERÊNCIAS}

ALVARES, C. A.; STAPE, J. L.; SENTELHAS, P. C.; GONÇALVES, J. L. M.; SPAROVEK, G.. Köppen's climate classification map for Brazil. Meteorologische Zeitschrift, v.22, n.3, p.711-728, 2013. DOI: http://dx.doi.org/10.1127/0941-2948/2013/0507

BALBINO, L. C.; CORDEIRO, L. A. M.; SILVA, V. P.; MORAES, A.; MARTÍNEZ, G. B.; ALVARENGA, R. C.; KICHEL, A. N.; FONTANELI, R. S.; SANTOS, H. P.; FRANCHINI, J. C.; GALERANI, P. R.. Evolução tecnológica e arranjos produtivos de sistemas de integração lavoura-pecuária-floresta no Brasil. Pesquisa Agropecuária Brasileira, Brasília, v.46, p.1-12, 2011. DOI: http://doi.org/10.1590/S0100$\underline{204 \times 2011001000001}$

BIONDI, C. M.; NASCIMENTO, C. W. A.; FABRICIO NETA, A. B.; RIBEIRO, M. R.. Teores de Fe, Mn, Zn, Ni e Co em solos de referência de Pernambuco. Revista Brasileira de Ciência do Solo, Viçosa, v.35, n.3, p.1057-1066, 2011. DOI: http://dx.doi.org/10.1590/S0100-06832011000300039

BOCARDI, J. M. B.; PLETSCH, A. L.; ROCHA, A. S.; QUINAIA, S. P.. Parâmetros físicos e químicos em solos de Unidades de Conservação Florestal da Bacia do Paraná 3, Brasil. Revista Brasileira de Geografia Física, v.11, n.1, p.99-113, 2018. DOI:

http://periodicos.ufpe.br/revistas/rbgfe/article/view/23421 1/pd.11DEZ.2018

BRASIL. Companhia de Pesquisa de Recursos Minerais. Mapas Geológicos 1:1.000.000. CPRM, 2006.

BROCH, D. L.; PAVINATO, P. S.; POSSENTTI, J. C.; MARTIN, T. 
N.; DEL QUIQUI, E. M.. Produtividade da soja no cerrado influenciada pelas fontes de enxofre. Revista Ciência Agronômica, Fortaleza, v.42, n.3, 791-796, 2011. DOI: http://doi.org/10.1590/S1806-66902011000300027

CAMPOS, J. R. R.; SILVA, A. C.; SILVA, E. B.; VIDAL-TORRADO, P.. Extração e quantificação de alumínio trocável em Organossolos. Pesquisa Agropecuária Brasileira, Brasília, v.49, n.3, p.207-14, 2014. DOI: http://doi.org/10.1590/S0100-204X2014000300007

CASSOL, C. J.; CORTIVO, N. S. D.; PLETSCH, A. L.; COSTA JÚNIOR, I. L.; GOMES, F. A. L.. Determinação de manganês disponível em solos de referência da Mesorregião Oeste do Paraná. Revista Online de Extensão e Cultura-Realização, v.5, n.9, p.21-27, 2018. DOI: http://doi.org/10.30612/reufgd.v5i9.8535

CLAESSEN, M. E. C.. Manual de métodos de análise de solo. 2 ed. Rio de Janeiro: EMBRAPA-CNPS, 1997.

CONAMA. Conselho Nacional do Meio Ambiente. Resolução no 420, de 28 de dezembro de 2009. CONAMA, 2009.

CORINGA, E. A. O.; COUTO, E. G.; PEREZ, X. L. O.; TORRADO, $P$. V.. Atributos de solos hidromórficos no Pantanal Norte Matogrossense. Acta Amazônica, Manaus, v.42, n.1, p.1928, 2012. DOI: http://dx.doi.org/10.1590/S004459672012000100003

CORRÊA, R. M.; FREIRE, M. B. G. S.; FERREIRA, R. L. C.; FREIRE, F. J.; PESSOA, L. G. M.; MIRANDA, M. A.; MELO, D. V. M.. Atributos químicos de solos sob diferentes usos em perímetro irrigado no semiárido de Pernambuco. Revista Brasileira de Ciência do Solo, Viçosa, v.33, n.02, 2009.

COSTA, R. D. S.; NETO, P. P.; CAMPOS, M. C. C.; NASCIMENTO, W. B.; NASCIMENTO, C. W. A.; SILVA, L. S.; CUNHA, J. M.. Teores naturais de metais pesados em solos da região Sul do Estado do Amazonas. Semina: Ciências Agrárias, Londrina, v.38, n.6, p.3499-3514, 2017. DOI: http://doi.org/10.5433/1679-0359.2017v38n6p3499

COSTA, T. G. A.; IWATA, B. F.; COELHO, J. V.; ROCHA, I. L.; SANTOS, J. G. P.; LEOPOLDO, N. C. M.; ALVES, M. F.; MACIEL, A. C. R.; CLEMENTINO, G. E. S.. Atributos de qualidade do solo sob fitofisionomias de cerrado sensu stricto e cerradão no Parque Nacional das Nascentes do Rio Parnaíba. Revista Brasileira de Gestão Ambiental e Sustentabilidade, João Pessoa, v.5, n.10, p.625-642, 2018. DOI: http://doi.org/10.21438/rbgas.051016

DONAGEMMA, G. K.; FREITAS, P. L.; BALIEIRO, F. C.; FONTANA, A.; SPERA, S. T.; LUMBRERAS, J. F.; VIANA, J. H. M.; ARAUJO FILHO, J. C.; SANTOS, F. C.; ALBUQUERQUE, M. R.; MACEDO, M. C. M.; TEIXEIRA, P. C.; AMARAL, A. J.; BORTOLON, E.; BORTOLON, L.. Caracterização, potencial agrícola e perspectivas de manejo de solos leves no Brasil. Pesquisa Agropecuária Brasileira, Brasília, v.51, n.9, p.10031020, 2016. DOI: http://doi.org/10.1590/S0100204X201600090000.

FAQUIN, V.. Nutrição Mineral de Plantas. Lavras: Universidade Federal de Lavras/FAEPE, 2005.

FELIX, J. C.; VENDRAME, P. R. S.; MARCHÃO, R. L.; OLIVEIRA, J. F.; GUIMARÃES, M. F.; BROSSARD, M.; BECQUER, T.;
BRITO, O. R.. Predição de fósforo, carbono e nitrogênio em solos de basalto, por meio de espectroscopia NIR. Pesquisa Agropecuária Brasileira, Brasília, v.51, n.9, p.1405-1416, 2016. DOI: http://dx.doi.org/10.1590/S0100$\underline{204 \times 2016000900039}$

FERNANDES, C. H. S.; TEJO, D. P.; ARRUDA, K. M. A. Desenvolvimento do Sistema de Plantio Direto no Brasil: Histórico, Implantação e Culturas Utilizadas. UNICIÊNCIAS, v.23, n.2, p.83-88, 2019. DOI:

http://dx.doi.org/10.17921/1415-5141.2019v23n2p83-88

FONSECA, J. A.; HANISCH, A. L.. Cinza de biomassa é um produto eficiente para uso em sistema de produção de cereais em base agroecológica? Revista de Ciências Agroveterinária, Lages, v.17, n.4, 2018. DOI: http://doi.org/10.5965/223811711732018454

FREITAS, L.; OLIVEIRA, I. A.; CASAGRANDE, J. C.; SILVA, L. S.; CAMPOS, M. C. C.. Estoque de carbono de Latossolos em sistemas de manejo natural e alterado. Ciência Florestal, Santa Maria, v.28, n.1, p.228-239, 2018. DOI: http://dx.doi.org/10.5902/1980509831575

GONÇALVES, M. A.; TELLES, T. S.; CAVIGLIONE, J. H.; URBANO, A.; FILHO, J. T.. Diferenciação dos solos em duas topossequências sobre rochas basálticas no norte-central paranaense. Semina: Ciências Agrárias, Londrina, v.34, n.6, p.2777-2792, 2013. DOI: http://dx.doi.org/10.5433/16790359.2013v34n6p2777

HONGYU, K.; SANDANIELO, V. L. M.; JUNIOR, G. J. O.. Análise de componentes principais: resumo teórico, aplicação e interpretação. E\&S - Engineering and Science, Cuiabá, v.5, n.1, 2015. DOI: http://doi.org/10.18607/ES20165053

IBGE. Instituto Brasileiro de Geografia e Estatística. Manual Técnico da Vegetação Brasileira. Rio de Janeiro: Manuais Técnicos em Geociências, 2012.

JOLLIFFE, L. T.. Principal component analysis. 2 ed. New York: Springer, 2002

KASEMODEL, M. C.; RODRIGUES, V. G. S.. Geological and Geotechnical Characterization of the Basal Soil Portion at a Former Mining Waste Disposal. Electronic Journal of Geotechnical Engineering, v.20, n.1, 2015.

KAISER, H. F.. The varimax criterion for analytic rotation in factor analysis. Psychometrika, v.23, n.3, p.187-200, 1958. DOI: http://doi.org/10.1007/BF02289233

KOCHIAN, L. V.; PIÑEROS, M. A.; LIU, J.; MAGALHAES, J. V.. Plant adaptation to acid soils: the molecular basis for crop aluminum resistance. Annual Review of Plant Biology, v.66, p.571-598, 2015. DOI: http://doi.org/10.1146/annurevarplant-043014-114822

LEITE, O.; MELO, M.; OLIVEIRA, L.; SOBRINHO, M.; MELO, B. Influência de dosagens de calcário em um latossolo vermelho-amarelo distrófico no Sul do Tocantins, Brasil. Enciclopédia Biosfera, Jandaia, v.15, n.28, 2018. DOI: http://doi.org/10.18677/EnciBio 2018B55

LOPES, E. R. N.; SOUZA, J. C.; FILHO, J. L. A.; LOURENÇO, R. W.. Caminhos e entraves do zoneamento ecológicoeconômico no Brasil. Caminhos de Geografia, Uberlândia, 
v.20, n.69, p.342-359, 2019. DOI:

http://dx.doi.org/10.14393/RCG206941305

MEDEIROS, J. C.; ALBUQUERQUE, J. A.; MAFRA, A. L.; ROSA, J. D.; GATIBONI, L. C.. Relação cálcio:magnésio do corretivo da acidez do solo na nutrição e no desenvolvimento inicial de plantas de milho em um Cambissolo Húmico Álico.

Semina, v.29, n.4, p.799-806, 2008. DOI:

http://dx.doi.org/10.5433/1679-0359.2008v29n4p799

MEURER, E. J.; RHENHEIMER, D.; BISSANI, C. A.. Fenômenos de Sorção em Solos. In: MEURER, E. J.. Fundamentos de química do solo. Porto Alegre, 2015. p.113-154.

MOLINE, E. F. V.; COUTINHO, E. L. M.. Atributos químicos de solos da Amazônia Ocidental após sucessão da mata nativa em áreas de cultivo. Revista Brasileira de Ciências Agrárias, Recife, v.58, n.1, p.14-20, 2015. DOI: http://dx.doi.org/10.4322/rca.1683

OLIVEIRA, F. C.; BENETT, C. G. S.; BENETT, K. S. S.; SILVA, L. M.; VIEIRA, B. C.. Diferentes doses e épocas de aplicação de zinco na cultura da soja. Revista de Agricultura Neotropical, Cassilândia, v.4, Suplemento 1, p.28-35, 2017.

PEREIRA, M. G.; SCHIAVO, J. A.; FONTANA, A.; DIAS NETO, A. H.; MIRANDA, L. P. M.. Caracterização e classificação de solos em uns topos sequência sobre calcário na serra da Bodoquena, MS. Revista Brasileira de Ciências do Solo, Viçosa, v.37, n.1, p.25-36, 2013. DOI: http://dx.doi.org/10.1590/S0100-06832013000100003

PAYE, H. S.; MELLO, J. W. C. V.; ABRAHÃO, W. A. P.; FERNANDES FILHO, E. I.; DIAS, L. C. P.; CASTRO, M. L. O.; MELO, S. B.; FRANÇA, M. M.. Valores de referência de qualidade para metais pesados em solos no Estado do Espírito Santo. Revista Brasileira de Ciência do Solo, v.34, n.6, p.2041-2051, 2010. DOI:

http://dx.doi.org/10.1590/S0100-06832010000600028

RAIJ, B. V.. Fertilidade do solo e manejo de nutrientes. Internacional Plant Nutrion Institute, 2011.

ROCHA, G. X.; PIERANGELI, M. A. P.; MARQUES, M. C. S.. Atributos de fertilidade dos solos as margens do Rio Paraguai, Pantanal de Cáceres/MT. Revista Ibero Americana de Ciências Ambientais, Aracaju, v.9, n.4, p.99-110, 2018. DOI: http://doi.org/10.6008/CBPC2179$\underline{6858.2018 .004 .0008}$

RODRÍGUEZ-EUGENIO, N.; MCLAUGHLIN, M.; PENNOCK, D.. Soil Pollution: a hidden reality. Rome: FAO, 2018

RONQUIM, C. C.. Conceitos de fertilidade do solo e manejo adequado para as regiões tropicais. Embrapa Monitoramento por Satélite. Campinas: Boletim de Pesquisa e Desenvolvimento, 2010.

SANTOS, F. F.; RESENDE, A. V.; FILHO, M. R. A.; BORIN, A. L. D. C.; PASSOS, A. M. A.. Dinâmica da fertilidade em solos frágeis. In: CASTRO, S. S.; HERNANI, L. C.. Solos frágeis: caracterização, manejo e sustentabilidade. Brasília: Embrapa, 2015. p.161-184.
SANTOS, H. G.; JACOMINE, P. K. T.; ANJOS, L. H. C.; OLIVEIRA, V. A.; LUMBRERAS, J. F.; COELHO, M. R.; ALMEIDA, J. A.; ARAUJO FILHO, J. C.; OLIVEIRA, J. B.; CUNHA, T. J. F.. Sistema Brasileiro de Classificação de Solos. 5 ed. Brasília: Embrapa, 2018.

SEMADE. Secretaria de estado de meio ambiente, e desenvolvimento econômico. Geoambientes da faixa de fronteira GTNF/MS. Campo Grande: SEMADE, 2016.

SKORUPA, A. L. A.; GUILHERME, L. R. G.; CURI, N.; SILVA, C. P. C.; SCOLFORO, J. R. S.; MARQUES, J. J. G. S. M.. Propriedades de solos sob vegetação nativa em Minas Gerais: distribuição por fitofisionomia, hidrografia e variabilidade espacial. Revista Brasileira de Ciência do Solo, v.36, n.1, p.11-22, 2012. DOI: http://dx.doi.org/10.1590/S0100$\underline{06832012000100002}$

SILVA, S. A.; LIMA, J. S. S.; ZUCOLOTO, M.. Distribuição espacial das frações granulométricas em um Latossolo Vermelho amarelo utilizando krigagem indicativa. Engenharia na Agricultura, Viçosa, v.19, n.3, p.195-202, 2011.

SILVA, G. R.; SENA, W. L.; MATOS, G. S. B.; FERNANDES, A. R.; GAMA, M. A. P.. Crescimento e estado nutricional da soja influenciados pela relação $\mathrm{Ca}: \mathrm{Mg}$ em solo do cerrado paraense. Revista de Ciências Agrárias, Belém, v.55, n1, p.52-57, 2012. DOI: http://dx.doi.org/10.4322/rca.2012.038

SILVA, G. F.; SANTOS, D.; SILVA, A. P.; SOUZA, J. M..

Indicadores de qualidade do solo sob diferentes sistemas de uso na mesorregião do agreste paraibano. Revista Caatinga, Mossoró, v.28, n.3, p.25-35, 2015. DOI: http://doi.org/10.1590/1983-21252015v28n303rc

SILVA, G. B. P.; ZANELLA, C. M.; DELATORRE, C. A.; CHAVES, M. S.; MARTINELLI, J. A.; FEDERIZZI, L. C.. Organic acid carriers in tolerance to toxic aluminum in wheat. Ciência Rural, Santa Maria, v.48, n.10, 2018. DOI: http://dx.doi.org/10.1590/0103-8478cr20180106

SOUSA, D. M. G.; LOBATO, E.. Cerrado: correção do solo e adubação 2 ed. Brasília: Embrapa Informação Tecnológica, 2004.

TEIXEIRA, P. C.; DONAGEMA, G. K.; FONTANA, A.; TEIXEIRA, W. G.. Manual de métodos de análise do solo. 3 ed. Brasília: Embrapa, 2017.

WERLE, R.; GARCIA, R. A.; ROSOLEM, C. A.. Lixiviação de potássio em função da textura e da disponibilidade do nutriente no solo. Revista Brasileira de Ciência do Solo, v.32, n.6, p.2297-2305, 2008. DOI: http://doi.org/10.1590/S0100-06832008000600009

ZAMBROSI, F. C. B.; ALLEONI, L. R. F.; CAIRES, E. F.. Teores de alumínio trocável e não trocável após calagem e gessagem em Latossolo sob plantio direto. Bragantia, Campinas, v.66, n.3, p.487-495, 2007. DOI: http://doi.org/10.1590/s0006$\underline{87052007000300016}$

A CBPC - Companhia Brasileira de Produção Científica (CNPJ: 11.221.422/0001-03) detém os direitos materiais desta publicação. Os direitos referem-se à publicação do trabalho em qualquer parte do mundo, incluindo os direitos às renovações, expansões e disseminações da contribuição, bem como outros direitos subsidiários. Todos os trabalhos publicados eletronicamente poderão posteriormente ser publicados em coletâneas impressas sob coordenação da Sustenere Publishing, da Companhia Brasileira de Produção Científica e seus parceiros autorizados. Os (as) autores (as) preservam os direitos autorais, mas não têm permissão para a publicação da contribuição em outro meio, impresso ou digital, em português ou em tradução. 